\title{
Health Insurance in Kenya
}

\author{
Evans Kiptoo Korir \\ MSc Actuarial Science, Dept. of Demography, Kariavattom campus
}

\begin{abstract}
Health insurance in Kenya was launched by the government in 1967 when they introduced National Health Insurance Fund (NHIF) to provide health care to Kenyans. Since then, the sector has grown widely due to liberalization of the industry and increase in the medical costs. In Kenya, the health care insurance is provided by both government and private insurers.
\end{abstract}

This article aims to study the concept, benefits, and the growth of the health insurance in Kenya. It also highlights the health insurance plans available in the country. The study is based on secondary data collected from journals, articles, and Insurance Regulatory Authority (IRA) website. To study the growth of the health insurance in the country, premium, claims, and expense of 22 insurance companies offering health insurance from 2010 to 2018 were taken into consideration. Microsoft Excel was utilized for the analysis. The paper outlined the concept, health insurance plans, and their importance to the insured. The paper also revealed that the premium, claims, and expenses of the insurance companies increased constantly during the study period.

Keywords:- Health Insurance, Premium, Claim, Policyholder, Sum Insured.

\section{INTRODUCTION}

A Health insurance policy provides financial protection to the insured person in the event of unforeseen and sudden accident/illness leading to hospitalisation. Recently, it has been realized as an effective way people can finance their medical care needs. For every Kenyan, health insurance has become a necessity. Presently, medical and hospitalization costs are inflated. Without insurance, it will prove costly. Swathi and Anuradha (2017) in their study stated that any family can live peacefully without worrying about their medical bills if they have insurance cover. The authors further highlighted that in case the family does not have any medical cover, unforeseen illness can adversely affect their financial situation. Therefore, it is advisable for an individual or a family to contribute a small amount as premium to the insurance company to achieve a peace of mind.

In Kenya, health insurance is low. Otieno et al. (2018) conducted a study in Viwandani slums, Nairobi based on the sample of 300 households to determine the health insurance coverage in the region. The authors found that only $43 \%$ of the households have insurance. While carrying out a study to determine coverage for maternal and child in the country,
Nguhiu, Barasa, and Chuma(2017) concluded that individuals are not getting effective health coverage from the existing cover.

Kenya has been experiencing health crisis for the last two decades. The country had a life expectancy of 51.74 in 2000 which has increased to 66.70 in 2020 . In 2000, the country was reporting 67.685 rate of infant mortality but currently the rate stands at 34.056. The death rate of the country dropped from 12.251 to 5.448 (2020). Furthermore, the population of the country has been growing at the rate of $2.28 \%$ from the year $2000(31,964,557)$ to $53,771,296$ in the year 2020 .

The public healthcare in the country is facing tremendous challenges as result of corruption and inadequate budget. This forced the government to seek conditional loans from organizations such as World Bank and IMF as early as 1980's which is now derailing the growth of the sector as the country has limited budget due to loans repayment. As a result, the sector is currently struggling in many ways ranging from suppliers to health worker's remuneration. This has forced many medical workers to seek employment in private healthcare facilities (Pacific Prime International, 2020).

In Kenya, health insurance is provided mainly by the 22 private insurers and 4 reinsurers as per the IRA (2018). However, with an aim to provide healthcare to all the people in the country, the government administered National Health Insurance Fund (NHIF). It is mandatory for the civil servants to join the fund and make contributions based on their salary. However, the fund is not properly administered and Kenyans find it difficult to access registered hospitals. Also, the contributions are not enough and people are forced to seek additional cover from the private insurers in the country to get full medical care cover.

As the provision of healthcare in the public facilities worsens, the private facilities are taking advantage of the situation. They have witnessed a growth in the sector as many Kenyans seek the medical care from their facilities. Private sectors have been able to introduce new products to suit their customer needs. Although their services are significantly high, the sector has managed to attract many Kenyans and foreign nationals. This shows the importance of the health insurance cover in the country.

$>$ Objectives of the Study

- To present the concept and the benefits of the health insurance in Kenya 
- To highlight the health insurance plans available in the country

- To study the growth of health insurance in Kenya

\section{$>$ Data and Methodology}

The study is based on secondary data. Data is collected from Insurance Regulatory Authority (IRA) website from 2010 to 2018 , website, journals, and articles. I studied health insurance products and analysed the growth of health insurance in Kenya based on the premium received, claims paid, and expense incurred by the insurance companies in the country. Microsoft Excel was utilized to produce the bar graph for the representation of the trend in the industry.

\section{LITERATURE REVIEW}

Swathi and Anuradha (2017) conducted a study on health insurance in India. The study is based on the secondary data from IRDA website, journals, and articles. The study presented the concept, benefits, and overview of the health insurance in the country. The study found out that private, public, and specialized insurers provide health insurance in the country. Also, that the insurance covered only inpatient services. The study concluded that individuals and family should contribute a small amount as premium to the insurance company to achieve a peace of mind.

Otieno et al. (2018) conducted a study in Viwandani slums, Nairobi to determine the prevalence of the health insurance in the region. A cross-sectional survey was done involving a sample of 300 households randomly selected in the slums. The respondents were individuals aged over 18 years in the household. The primary outcome was to find out whether the respondents have health insurance cover or not. The findings of the study reported that only $43 \%$ of the households have health insurance. The authors concluded that the prevalence of the health insurance in the country is still low.

Nguhiu, Barasa, and Chuma (2017) made a study to determine coverage for maternal and child in the country. The study utilized surveys from Demographic Health from 2003 to 2014 and Service Provision Assessment from 2004 to 2010. The authors measured effective coverage using indicators such as need, quality, and use. From the study, there was an increase in effective coverage from $26.7 \%$ (2003) to $50.9 \%$ (2014). In 2003, wealth quintile ratio was recorded as 2.41 and later decreased to 1.65 (2014). The study concluded that health services relating to child and mothers are still low and inequitable in the country.

Kazungu and Barasa (2017) examined the levels associated with the health insurance coverage In Kenya. The study was based on the secondary data from the year 2009 to 2014 collected from the Kenya Demographic and Health Survey. To carry out the study, the households were ranked on an index from 1 (poor) to 5 (richest). To analyze level and distribution of the insurance coverage, concentration curve and index were applied. The authors employed logistic regression to deduce the relationship of the coverage. The study found out that the coverage of the insurance increase during the studying period from 8.7 percent to 19.59 percent. Authors concluded that the health insurance coverage is still low and not equally distributed in the country.

Okungu, Chuma, and McIntyre (2017) made a study on the cost of free health care in the country. The study critically analyzed the necessary financial requirements for achieving universal health coverage in the country. The study ascertains whether social health insurance or noncontributory scheme is the best option for achieving the insurance coverage in Kenya. The study was based on the secondary data for a period of 17 years from 2013 to 2030. Information such as inflation, health insurance, demography, and macro-economic was collected from the website. To measure feasibility of the cover, SimIns Basic $₫$ model was utilized. The study revealed that social health insurance is financially sustainable but the sustainability decreases with time. However, non-contributory scheme proved sustainability during the entire study period.

\section{Concept}

Health insurance in the country offer both inpatient and outpatient services based on the cover selected by an individual. The health insurance was first transacted by the National Hospital Insurance Fund (NHIF) which was established in the year 1967 by an act of parliament. However, with liberalization of the insurance sector, the private sector joined the business. As per the IRA (2018), the health insurance cover is transacted by 22 insurers and 4 reinsurers. Opening of the insurance sector led to the emergence of innovative health insurance products and also helped in a widespread of insurance. Thus, liberalization brought in competitions and better customer service.

\section{BENEFITS OF HEALTH INSURANCE IN KENYA}

\section{$>$ Hospitalization costs coverage}

In the event that the insured gets hospitalized in the hospital, the insurance company will pay the hospitalization costs. The costs include bed and treatment. These costs increase the medical costs and if not covered by the insurer, the patient might suffer mentally from the expenses which might derail his/her recovery.

\section{$>$ Consultation costs coverage}

In a given year, there is a high possibility that the insured will need to consult a doctor on his/her health. The costs for such consultation can go up as thousands in high level hospitals in the country. This coverage is always provided by the insurers and it is the first benefit an insured can enjoy.

\section{$>$ Medicine costs coverage}

In most cases after visiting a hospital, dosage of medicine is always prescribed which will aid in the patients' recovery process. Such medicines can be bought from the chemists accredited with the hospital or in the hospital pharmacy. Insured will not be required to incur such expenses relating to the medicine. 
ISSN No:-2456-2165

\section{Other allied benefits coverage}

The insured can pay more premiums to get other benefits which may not necessarily relate to the medical care. Such benefits include consultation with specialists, coupons on healthcare costs, lab work, and ambulance costs.

\section{$>$ Protection of the finances}

The main aim of the health insurance is to meet unforeseen costs relating to illness and thus it does not interfere with personal savings.

\section{HEALTH INSURANCE PLANS IN KENYA}

\section{Hospitalization plan}

This plan covers the hospitalization costs such as bed and treatment. The sum assured depends on the premium and age of the insured.

\section{Family Floater Health Insurance}

This plan caters to the medical needs of the family. In this cover, insurance companies allow medical insurance coverage for two adults and two children in the family. The sum assured can be shared by family members in no fixed proportion.

\section{All Pre-Existing Disease Cover Plans}

This plan covers proposers suffering from already preexisting dieses such as asthma, diabetes, cancer, and blood pressure. For this people, buying a comprehensive plan can prove expensive. However, this group of people has to pay a higher premium to get covered.

\section{Senior Citizen Health Insurance}

This plan covers old people only between the age 60 and 75 years. It covers hospitalization costs, day care, tax benefits, and pre-existing conditions.

\section{$>$ Maternity Health Insurance}

This plan covers expenses related to delivery and other additional costs. In most cases, it is usually 30 days prehospitalization and 60 days post-hospitalization.

\section{Dospital daily cash benefit plans}

This plan provides a fixed sum to the insured for each day of hospitalization.

\section{$>$ Critical illness plans}

Most people suffer from critical illnesses such as cancer, stroke, and heart attack which are costly to treat. Thus, this plan protects the financial position of the insured once diagnosed with any of the critical illness. Insurance companies can cover up to 20 critical illnesses.

\section{Disease specific special plans}

This plan caters for the entire treatment of a certain disease such as Typhoid. With the introduction of such plans, customers have found the premium affordable.

\section{ANALYSIS OF THE GROWTH OF HEALTH INSURANCE IN KENYA}

\begin{tabular}{|c|c|c|c|}
\hline Year & $\begin{array}{c}\text { Premium } \\
\text { received }\end{array}$ & Claims paid & $\begin{array}{c}\text { Expense } \\
\text { incurred }\end{array}$ \\
\hline 2010 & $5,626,452$ & $4,729,223$ & 963,639 \\
\hline 2011 & $6,344,416$ & $5,248,086$ & $1,279,921$ \\
\hline 2012 & $8,440,074$ & $6,538,485$ & $1,857,500$ \\
\hline 2013 & $12,433,137$ & $9,260,252$ & $2,943,862$ \\
\hline 2014 & $16,474,600$ & $12,774,064$ & $3,768,534$ \\
\hline 2015 & $19,929,257$ & $15,063,107$ & $4,488,071$ \\
\hline 2016 & $23,920,288$ & $18,095,201$ & $5,686,204$ \\
\hline 2017 & $28,399,766$ & $20,632,162$ & $5,973,951$ \\
\hline 2018 & $27,133,652$ & $20,515,402$ & $6,447,497$ \\
\hline
\end{tabular}

Table 1: premium received, claims paid, and expense incurred by the insurance companies offering health insurance in Kenya from 2010-2018

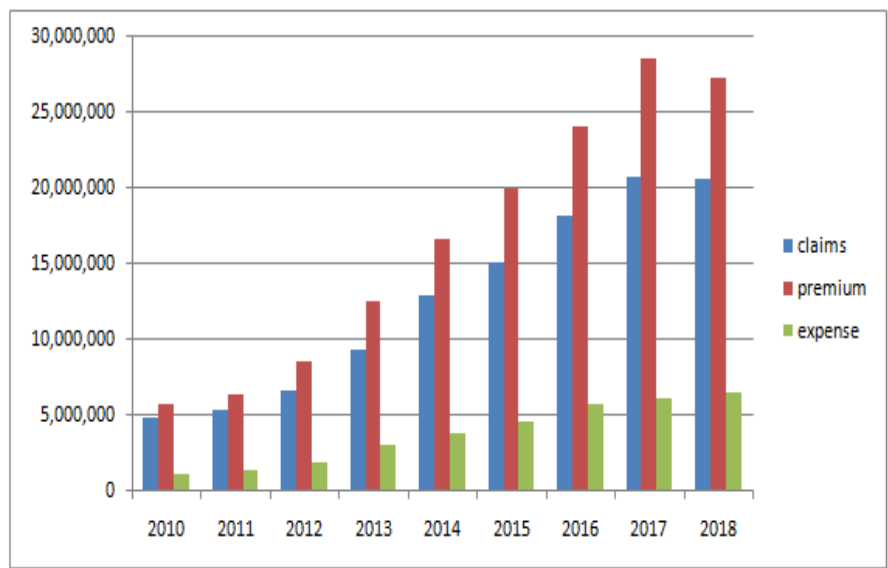

Fig 1:- premium, claims, and expenses trend from 20102018

From the above analysis, it is evident that the premium, claims, and the expenses incurred by the insurance companies in Kenya offering health insurance cover has been increasing constantly from 2010 to 2018 . In the year 2010, the insurance companies just reported KES $5,626,452$ premium and it quintuple to KES 27,133,652 in 2018. Similarly, the claims increased about 5 times yearly from KES 4,729,223 in 2010 to KES 20,515,402. As the premium and claims increases, the expenses of the insurance companies increase as well. It can be seen from the figure that the expense management of the insurers increased about 6 times from KES 963,639 to KES 6,447,497 in 2018.

In all the years, the premium received by the insurance companies is not wholly utilized in the payment of the claims. From the figure, the premiums are higher than the claims at any given year. This confirms that the insurance companies are making profit and some funds remaining for those companies are reinvested and used in research and development of more health insurance products to suit the needs of the customer. Since the premium, claims, and expenses are increasing, it can be concluded that the insurance companies are experiencing high number of policyholders, and as such the health insurance sector in the country is growing. The increase in the number of 
policyholders is due to high demand in the health insurance arising from huge medical bills in the country.

\section{CONCLUSION}

High and inflated medical costs can severely affect the savings of an individual or a family. It is advisable that Kenyans should pay a small premium to the insurance companies and take any health insurance cover based on their needs to mitigate any financial losses arising from unforeseen illnesses. They should avail health insurance cover to live peacefully without worrying about medical bills.

\section{REFERENCES}

[1]. Jacob S Kazungu, Edwine W Barasa (2017). Examining levels, distribution and correlates of health insurance coverage in Kenya)

[2]. https://onlinelibrary.wiley.com/doi/full/10.1111/tmi.12 912

[3]. K.Swathi and R.Anuradha. (2017). Health Insurance in India-An Overview

[4]. http://www.iosrjournals.org/iosrjbm/papers/Conf.17037-2017/Volume-7/10.\%204952.pdf

[5]. Macrotrends.net. 2020. Kenya Life Expectancy 19502020. [online] Available at: https://www.macrotrends.net/countries/KEN/kenya/lif e-expectancy [Accessed 25 September 2020].

[6]. Pacificprime.com. 2020. Kenya Health Insurance | Pacific Prime International. [online] Available at: https://www.pacificprime.com/country/africa/kenyahealth-insurance/ [Accessed 25 September 2020].

[7]. Peter K Nguhiu,Edwine W Barasa, Jane Chuma (2017).Determining the effective coverage of maternal and child health services in Kenya, using demographic and health survey data sets: tracking progress towards universal health coverage

[8]. https://pubmed.ncbi.nlm.nih.gov/28094465/

[9]. Peter O Otieno, Elvis Omondi Achach Wambiya, Shukri F Mohamed, Hermann, Pythagore Pierre Donfouet, Martin K Mutua. (2018). Prevalence and factors associated with health insurance coverage in resource-poor urban settings in Nairobi, Kenya: a cross-sectional study.

[10]. https://bmjopen.bmj.com/content/9/12/e031543

[11]. Suchman, L. (2018). Accrediting private providers with National Health Insurance to better serve lowincome populations in Kenya and Ghana: a qualitative study. Int $J$ Equity Health 17, $179 \quad$ (2018). https://doi.org/10.1186/s12939-018-0893-y

[12]. Vincent Okungu, Jane Chuma, Di McIntyre (2017). The cost of free health care for all Kenyans: assessing the financial sustainability of contributory and noncontributory financing mechanisms

[13]. https://equityhealthj.biomedcentral.com/articles/10.11 86/s12939-017-0535-9 